\title{
Temperatura ideal de germinação para sementes de citrumeleiro 'swingle'
}

\author{
Paulo Artur Konzen Xavier de Mello Silva \\ Instituto Federal de Educação, Ciência e Tecnologia do Rio Grande do Sul (IFRS) \\ Campus Porto Alegre \\ (paulo.xavier@poa.ifrs.edu.br)
}

\begin{abstract}
Resumo: O Citrumeleiro 'Swingle' é um híbrido obtido do cruzamento de pomelo 'Duncan' (Citrus paradisi Macf.) com limão bravo (Poncirus trifoliata L.). Para a produção de porta-enxertos de plantas cítricas é utilizada a propagação por sementes. Quando se considera o custo de produção de mudas cítricas em ambiente protegido, o tempo de formação da muda é muito importante, por isso é relevante o estudo dos fatores que contribuem para a rápida germinação das sementes. E a temperatura é um dos principais fatores que influenciam na germinação das sementes. Logo, o objetivo dessa pesquisa foi avaliar a germinação das sementes do porta-enxerto Citrumeleiro 'Swingle' em diferentes temperaturas (constantes e alternada) tais como: $20^{\circ} \mathrm{C}, 25^{\circ} \mathrm{C}$ e $30^{\circ} \mathrm{C}$ e $20-$ $30^{\circ} \mathrm{C}$. Os resultados indicam que a temperatura ideal para a germinação das sementes de Citrumeleiro cv Swingle é de $30^{\circ} \mathrm{C}$ constante superando os demais tratamentos térmicos com relação à velocidade de germinação.
\end{abstract}

Palavras-chave: Citrus; Análise de sementes, Teste de germinação.

\section{Ideal germination temperature for 'swingle' citrus seeds}

\begin{abstract}
The Citrumeleiro 'Swingle' is a hybrid obtained by crossing pomelo 'Duncan' (Citrus paradisi Macf.) with trifoliate orange (Poncirus trifoliata L.). Seed propagation is used for the production of rootstocks of citrus plants. When considering the cost of production of citrus seedlings in protected environment, the time of seedling formation is very important, so it is relevant to study the factors that contribute to the rapid germination of the seeds. And temperature is one of the main factors that influence seed germination. Therefore, the objective of this research was to evaluate the germination of the Citrumeleiro 'Swingle' rootstock at different temperatures (constants and alternating) such as: $20^{\circ} \mathrm{C}, 25^{\circ} \mathrm{C}$ and $30^{\circ} \mathrm{C}$ and $20-30^{\circ} \mathrm{C}$. The results indicate that the ideal temperature for the germination of Citrumeleiro cv Swingle seeds is $30^{\circ} \mathrm{C}$ constant, surpassing other heat treatments in relation to the germination speed.
\end{abstract}

Keywords: Citrus; seed analysis; Germination test.

\section{INTRODUÇÃO}

O Citrumeleiro 'Swingle' é um híbrido obtido na Florida em 1907 pelo cientista Walter Tennyson Swingle, que polinizou flores de pomelo 'Duncan' (Citrus paradisi Macf.) com pólen de flores de limoeiro bravo (Poncirus trifoliata L.). O objetivo inicial 
era transferir a resistência a geadas do limão para os pomelos, muito suscetíveis ao frio da Florida (SANTOS, 2015). A principal característica do híbrido criado batizado com o nome de seu criador, "Swingle", é a sua resistência à Gomose (Phytophthora spp), ao Nematóide dos citros (Tylenchulus semipenetrans Cobb.) e ao frio que é igual ou superior a dos porta-enxertos tradicionalmente utilizados na citricultura. Além disso, o Swingle tem mostrado, até o momento, uma tolerância superior a uma anomalia vascular recorrente denominada "Declínio dos citros" (ARAÚJO et al., 2007).

No Brasil, segundo Oliveira et al. (2008), 100\% da produção de porta-enxertos cítricos, de uso comercial, são obtidos a partir de sementes. Quando se considera o custo de produção de citros em ambiente protegido, o tempo de formação da muda é muito importante, pois, diminuindo o tempo de permanência da muda no viveiro, se aumenta o número de ciclos de produção de mudas, durante a vida útil da estrutura física, desta forma, otimizando a mão-de-obra e reduzindo os gastos com defensivos agrícolas e fertilizantes (TEIXEIRA et al., 2009).

O valor das sementes e da estrutura do sistema de produção de mudas em ambiente protegido é alto e requer grande uniformidade na germinação das sementes e na emergência das plântulas. Uma vez que a variabilidade da germinação acarreta posterior desuniformidade das plantas ao longo do processo de produção de mudas. Para a obtenção de porta-enxertos vigorosos e uniformes, necessita-se utilizar sementes com boa qualidade genético-sanitária e condições favoráveis à germinação e ao desenvolvimento das plântulas. Neste sentido, faz-se necessário testar tratamentos que proporcionem uniformidade na germinação de sementes das diversas cultivares de porta-enxertos de citros (TEIXEIRA et al., 2009).

A temperatura em que ocorre a germinação de sementes é um fator muito importante, tanto no aspecto de germinação total como na velocidade de germinação, pois a temperatura influencia a velocidade de absorção de água e as reações bioquímicas que ocorrem durante o processo (CARVALHO e NAKAGAWA, 2000). As variações da temperatura afetam a velocidade, a porcentagem e a uniformidade da germinação (MARCOS FILHO, 2005). As sementes apresentam comportamento variável frente a esse fator, não havendo uma temperatura ótima e uniforme para todas as espécies; a faixa de $20^{\circ} \mathrm{C}$ a $30^{\circ} \mathrm{C}$ tem sido adequada para grande número de espécies subtropicais e tropicais (BORGES e RENA, 1993). 
Os citros têm sua origem na Ásia tropical e subtropical, região com temperatura média mais elevada e grande umidade. Provavelmente, as condições ambientais benéficas para os indivíduos adultos, também proporcionam as melhores condições para a germinação das sementes de citros. Segundo Oliveira e Scivittaro (2007), o desenvolvimento dos porta-enxertos é otimizado em temperaturas de 26 a $28^{\circ} \mathrm{C}$.

Diversos trabalhos realizados com espécies arbóreas nativas do Brasil mostraram que, em temperatura constante, entre 20 e $30^{\circ} \mathrm{C}$, as sementes germinam bem, mas apresentam um melhor desempenho germinativo em temperatura alternada (SANTOS e AGUIAR, 2005). A alternância da temperatura corresponde a uma adaptação das espécies às flutuações naturais do ambiente (BORGES e RENA, 1993), principalmente às flutuações diárias (MAYER e POLJAKOFFMAYBER, 1982). Flutuações da temperatura geralmente promovem a germinação das sementes, provavelmente pela mudança das propriedades físicas do tegumento e na ativação das diferentes etapas metabólicas da germinação (CARDOSO, 1992).

Devido a importância comercial da produção de porta-enxertos e a carência de informação quanto a temperatura adequada para germinação de sementes de Citrumeleiro 'Swingle', esse trabalho de pesquisa visa comparar diversos tratamentos térmicos na germinação de sementes para recomendar a temperatura que promove maior velocidade de germinação.

\section{MATERIAIS E MÉTODOS}

O trabalho foi desenvolvido no Laboratório de Análise de Sementes do Departamento de Produção Vegetal da Escola Superior de Agricultura Luiz de Queiroz (ESALQ), em Piracicaba, SP.

As sementes utilizadas foram extraídas de frutos maduros colhidos de dezenas de árvores do pomar da ESALQ em Piracicaba, SP. As sementes foram processadas manualmente, submergindo-as em água e esfregando em peneira para a retirada da mucilagem externa, expostas em temperatura ambiente sobre papel por 48h para secar e, em seguida, acondicionadas em saco de papel e mantidas armazenadas em ambiente refrigerado à $4^{\circ} \mathrm{C}$, por 10 dias. Para determinação do teor de água das sementes foi utilizado o método da estufa a $105 \pm 3^{\circ} \mathrm{C}$ por 24 horas, de acordo com as Regras para Análise de Sementes (BRASIL, 2009). 
Para o teste de germinação o experimento foi conduzido com quatro repetições de 25 sementes em cada tratamento acondicionadas em caixas plásticas de $21 \times 14 \times 6,5 \mathrm{~cm}$, com tampa, em germinadores de câmara com temperatura constante. Antes da semeadura, com ajuda de uma pinça, foi removido o tegumento externo das sementes para evitar a desuniformidade de germinação observada por Oliveira e Scivittaro (2007). Como substrato foi utilizado areia autoclavada a $120^{\circ} \mathrm{C}$ por 60 minutos, segundo as Regras para Análise de Sementes (BRASIL, 2009) e a semeadura efetuada sobre o substrato umedecido com água destilada. A quantidade de água adicionada foi calculada segundo a granulometria da areia e sua capacidade de retenção (BRASIL, 2009).

Foram feitas análises periódicas para avaliar o número de sementes germinadas (percentual de germinação), considerando o critério botânico de germinação (protusão radicular). Além disso, houve avaliação da manifestação de poliembrionia nas sementes nos diversos tratamentos.

No experimento de germinação foram testadas as temperaturas constantes de 20,25 e $30^{\circ} \mathrm{C}$ e alternada de $20-30^{\circ} \mathrm{C}$. Na temperatura alternada foi adotado o período de $8 \mathrm{~h}$ à $30^{\circ} \mathrm{C}$ e $16 \mathrm{~h}$ à $20^{\circ} \mathrm{C}$, nestas condições as caixas eram trocadas manualmente de germinadores.

O delineamento experimental foi em blocos inteiramente casualizados (4 repetições $X 4$ tratamentos) e com a comparação das médias pelo teste de Tukey, em nível de $5 \%$ de probabilidade.

Os parâmetros analisados no experimento foram: germinação da semente, semente germinada com comprimento de raiz com mais de $1 \mathrm{~cm}$, semente germinada com duas raízes e emergência do epicótilo. As observações foram realizadas em 7, 13, 20 e 26 dias após a instalação do experimento. Além disso, houve a contagem final do teste de germinação aos 50 dias após a semeadura, onde foram analisados o número de plantas normais ( $P N)$, o número de plantas anormais (PA) e as sementes não germinadas (SNG) nos quatro diferentes tratamentos (temperaturas de germinação).

\section{RESULTADOS E DISCUSSÃO}

No momento da instalação do experimento as sementes de Citrumelo 'Swingle' apresentavam teor de água em torno de $22 \%$. A retirada do tegumento 
para análise do grau de umidade não afetou os resultados. Os valores encontrados são semelhantes aos relatados por Siqueira et al. (2002) que observaram grau de umidade de $21,42 \%$ para sementes de porta-enxertos 'Swingle' armazenados sob refrigeração.

$\mathrm{Na}$ Tabela 1 podemos observar que a germinação das sementes de Citrumeleiro 'Swingle' foi mais rápida no tratamento à $30^{\circ} \mathrm{C}$ em relação aos outros tratamentos. Resultado semelhante foi também encontrado por Figliolia et al. (2009) e Araújo Neto e Aguiar (2000), trabalhando com arbóreas brasileiras. Na análise aos 7 dias, podemos observar que o tratamento à $25^{\circ} \mathrm{C}$ constante e o de temperatura alternada $\left(20-30^{\circ} \mathrm{C}\right)$ não diferiram estatisticamente. Entretanto, se observarmos o critério de sementes germinadas com $1 \mathrm{~cm}$ de raiz nas duas análises posteriores (13 e 20 dias) houve diferença estatisticamente significante, colocando o tratamento à $25^{\circ} \mathrm{C}$ em segundo lugar e o de temperatura alternada $\left(20-30^{\circ} \mathrm{C}\right)$ em terceiro na ordem de velocidade de germinação.

$\mathrm{Na}$ análise realizada aos 26 dias, quando a germinação das sementes não permite encontrarmos diferença estatística entre os tratamentos, ainda podemos elencar o tratamento à $30^{\circ} \mathrm{C}$ como o melhor, pois apresenta diferença significativa na emergência do epicótilo (Tabela 1).

No experimento para verificar a influência da temperatura na emergência dos porta-enxertos cítricos, Wiltbank et al. (1995) observou-se que o Poncirus trifoliata L. levou 80 dias para iniciar a emergência a temperaturas de $15-20^{\circ} \mathrm{C}$, mas, quando a faixa de temperatura oscilou de $30-35^{\circ} \mathrm{C}$, reduziu o tempo de germinação para 14 a 30 dias.

Levando em consideração o critério adotado para avaliar a poliembrionia (sementes germinadas com duas raízes) podemos observar que os tratamentos térmicos diferenciais não provocaram diferença estatisticamente significante, confirmando que esta característica possui um forte componente genético e que não se altera com a mudança desse fator ambiental. Este dado é importante, visto que um maior número de embriões por semente aumenta a proporção de embriões menores que, ao emergirem, têm um crescimento inicial menor, aumentando o período de formação da muda (SCHÄFER et al., 2005). 
Tabela 1 - Médias das quatro análises realizadas (7, 13, 20 e 26 dias) para os parâmetros de germinação da semente, semente germinada com comprimento de raiz com mais de 1 $\mathrm{cm}$, semente germinada com duas raízes e emergência do epicótilo em sementes de Citrumeleiro 'Swingle' tratadas com quatro diferentes temperaturas de germinação $\left(20^{\circ} \mathrm{C}\right.$; $\left.25^{\circ} \mathrm{C} ; 30^{\circ} \mathrm{C} ; 20-30^{\circ} \mathrm{C}\right)^{*}$.

\begin{tabular}{ccccc}
\hline Tratamento & Germinação & Raiz (1 cm) & Raiz dupla & Epicótilo \\
\hline \multicolumn{5}{c}{ Análise com 7 dias } \\
\hline 20 & $1,25 \mathrm{c}$ & $0,00 \mathrm{c}$ & $0,00 \mathrm{a}$ & $0,00 \mathrm{a}$ \\
25 & $9,00 \mathrm{~b}$ & $6,50 \mathrm{~b}$ & $2,25 \mathrm{a}$ & $0,00 \mathrm{a}$ \\
30 & $15,00 \mathrm{a}$ & $10,75 \mathrm{a}$ & $2,25 \mathrm{a}$ & $0,00 \mathrm{a}$ \\
$20-30$ & $5,75 \mathrm{bc}$ & $2,25 \mathrm{c}$ & $1,50 \mathrm{a}$ & $0,00 \mathrm{a}$ \\
\hline \multicolumn{5}{c}{ Análise com 13 dias } \\
\hline 20 & $4,50 \mathrm{c}$ & $1,25 \mathrm{c}$ & $1,00 \mathrm{a}$ & $0,00 \mathrm{c}$ \\
25 & $15,25 \mathrm{~b}$ & $14,00 \mathrm{~b}$ & $5,75 \mathrm{a}$ & $3,00 \mathrm{~b}$ \\
30 & $22,75 \mathrm{a}$ & $21,25 \mathrm{a}$ & $5,25 \mathrm{a}$ & $11,75 \mathrm{a}$ \\
$20-30$ & $13,50 \mathrm{~b}$ & $11,25 \mathrm{~b}$ & $5,00 \mathrm{a}$ & $0,00 \mathrm{c}$ \\
\hline \multicolumn{5}{c}{ Análise com 20 dias } \\
\hline 20 & $12,75 \mathrm{c}$ & $10,50 \mathrm{c}$ & $4,50 \mathrm{a}$ & $0,00 \mathrm{~d}$ \\
25 & $21,00 \mathrm{~b}$ & $18,00 \mathrm{~b}$ & $5,25 \mathrm{a}$ & $11,75 \mathrm{~b}$ \\
30 & $24,50 \mathrm{a}$ & $23,75 \mathrm{a}$ & $7,50 \mathrm{a}$ & $19,25 \mathrm{a}$ \\
$20-30$ & $20,00 \mathrm{~b}$ & $17,25 \mathrm{~b}$ & $6,25 \mathrm{a}$ & $6,25 \mathrm{c}$ \\
\hline \multicolumn{5}{c}{ Análise com 26 dias } \\
20 & $15,25 \mathrm{~b}$ & $14,25 \mathrm{~b}$ & $5,25 \mathrm{a}$ & $2,00 \mathrm{c}$ \\
25 & $22,50 \mathrm{a}$ & $22,00 \mathrm{a}$ & $6,50 \mathrm{a}$ & $16,25 \mathrm{~b}$ \\
$20-30$ & $24,50 \mathrm{a}$ & $24,25 \mathrm{a}$ & $8,75 \mathrm{a}$ & $23,00 \mathrm{a}$ \\
\hline 0 & $22,50 \mathrm{a}$ & $22,25 \mathrm{a}$ & $6,50 \mathrm{a}$ & $15,50 \mathrm{~b}$
\end{tabular}

${ }^{*}$ Em cada coluna, para cada parâmetro, dentro de cada análise realizada, médias seguidas de mesma letra não diferem entre si a $1 \%$ de probabilidade, pelo teste de Tukey.

O gráfico das avaliações do percentual germinativo das sementes nos diversos tratamentos (Figura 1) demonstra a velocidade germinativa e o rápido alcance de grande percentual germinativo no tratamento a $30^{\circ} \mathrm{C}$ em comparação com os outros tratamentos. 
Figura 1- Percentual de germinação das sementes nas quatro avaliações realizadas.

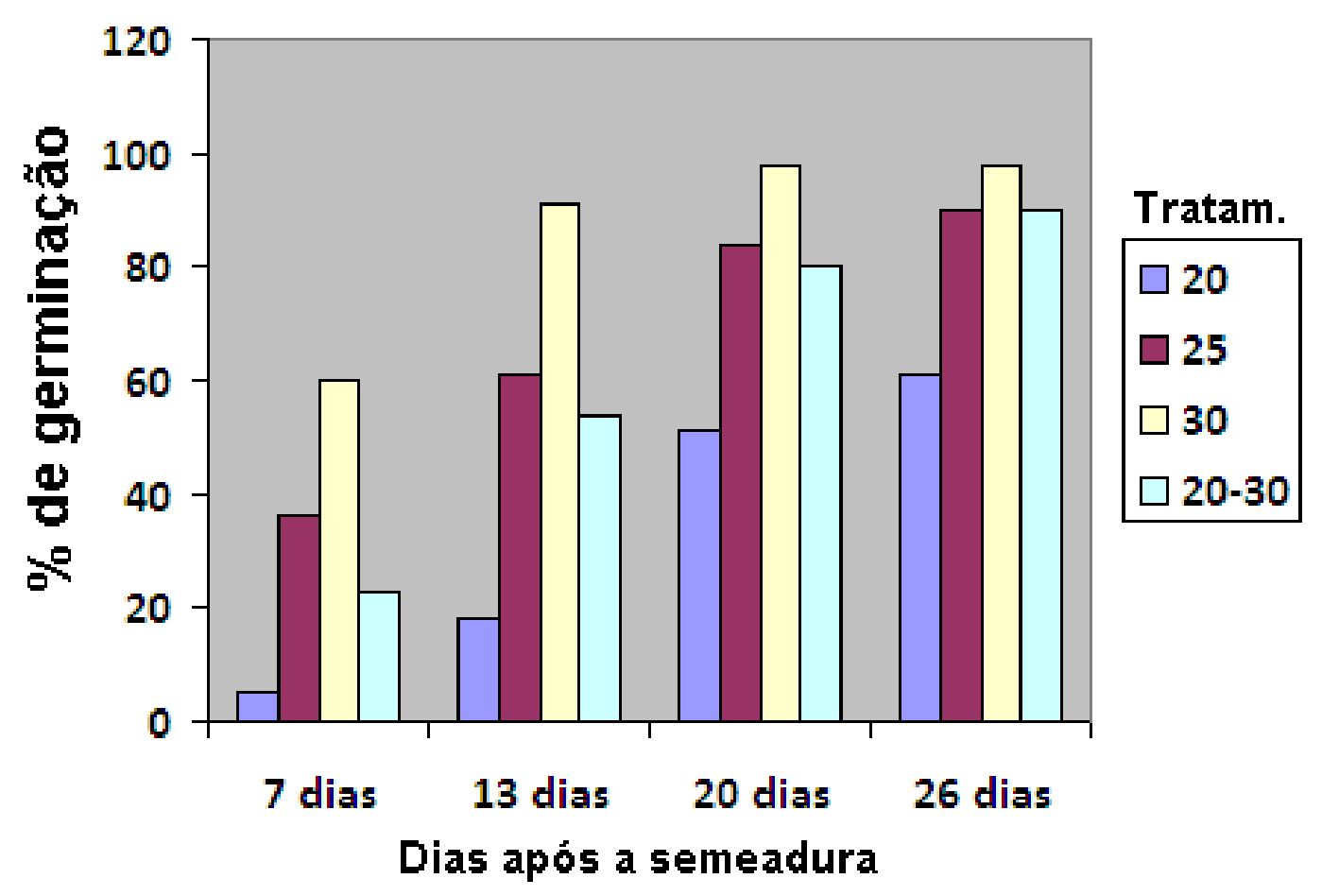

Com exceção do tratamento a $20^{\circ} \mathrm{C}$, os outros tratamentos não apresentam diferença estatisticamente significante no alcance do potencial máximo de germinação aos 26 dias após a semeadura. O resultado sugere recomendar temperatura de germinação mais alta que $20^{\circ} \mathrm{C}$ para as sementes de Citrumeleiro 'Swingle'.

$\mathrm{Na}$ contagem final do teste de germinação, aos 50 dias após a semeadura (Tabela 2), observamos que não houve diferença estatisticamente significante na emergência de plantas normais e no surgimento de plantas anormais. O que significa que apesar dos tratamentos germinativos com temperaturas diferentes apresentarem variação na velocidade de germinação das sementes, não diferiram no resultado estatístico final em relação ao número de plantas emergidas. $O$ resultado é semelhante para plantas anormais nos diferentes tratamentos, provavelmente, indicando que a característica está determinada geneticamente. Houve um número maior de sementes não germinadas, estatisticamente significante, no tratamento a $20^{\circ} \mathrm{C}$, provavelmente pela demora na germinação e eventual contaminação das sementes. 
Tabela 2 - Resultado da contagem final do teste de germinação aos 50 dias após a semeadura, apresentando as médias de plantas normais (PN), plantas anormais (PA) e sementes não germinadas (SNG) nos quatro diferentes tratamentos (temperaturas de germinação: $20^{\circ} \mathrm{C} ; 25^{\circ} \mathrm{C} ; 30^{\circ} \mathrm{C} ; 20-30^{\circ} \mathrm{C}$ ) em sementes de Citrumeleiro 'Swingle'.

\begin{tabular}{cccl}
\hline Tratamento & $\mathrm{PN}^{*}$ & $\mathrm{PA}^{*}$ & $\mathrm{SNG}^{* *}$ \\
\hline 20 & $21,00 \mathrm{a}$ & $0,25 \mathrm{a}$ & $3,75 \mathrm{a}$ \\
25 & $22,00 \mathrm{a}$ & $1,25 \mathrm{a}$ & $1,75 \mathrm{ab}$ \\
30 & $23,00 \mathrm{a}$ & $1,25 \mathrm{a}$ & $0,75 \mathrm{~b}$ \\
$20-30$ & $23,25 \mathrm{a}$ & $1,00 \mathrm{a}$ & $0,75 \mathrm{~b}$
\end{tabular}

*Em cada coluna, para cada parâmetro, médias seguidas de mesma letra não diferem entre si a $1 \%$ de probabilidade, pelo teste de Tukey.

${ }^{* *}$ No parâmetro SNG, médias seguidas de mesma letra não diferem entre si a $5 \%$ de probabilidade, pelo teste de Tukey.

\section{CONCLUSÕES}

1. A velocidade de germinação das sementes e a emergência das plântulas de Citrumeleiro 'Swingle' são maiores em temperatura constante de $30^{\circ} \mathrm{C}$.

2. A manifestação poliembriogênica nas sementes de Citrumeleiro 'Swingle' independe da temperatura de germinação, bem como o número de plântulas anormais.

3. A qualidade das sementes de Citrumeleiro 'Swingle' não é alterada pela temperatura de germinação.

\section{AGRADECIMENTOS}

Agradeço a professora Dra. Ana Dionísia da Luz Coelho Novembre pelos ensinamentos e pela concessão de espaço no laboratório de análise de sementes ESALQ/USP para realizar os meus experimentos.

\section{REFERÊNCIAS}

ARAÚJO, P.O.L.C.; GONÇALVES, F.C.; RAMOS, J.D.; CHALFUN, N.N.J.; CARVALHO, G.J. Crescimento e percentual de emergência de plântulas de 
citrumeleiro 'Swingle' em função dos substratos e das doses de corretivo à base de Lithothamnium, após cem dias da semeadura. Ciência Agrotécnica. v.31, n.4, Lavras, Jul/Ago, 2007.

ARAÚJO NETO, J. C.; AGUIAR, I. B. Germinative pretreatments to dormancy break in Guazuma ulmifolia Lam. seeds. Scientia Forestalis, Piracicaba, n. 58, p. 15-24, 2000.

BORGES, E.E.L.; RENA, A.B. Germinação de sementes. In: AGUIAR, I.B.; PIÑARODRIGUES, F.C.M.; FIGLIOLIA, M.B. Sementes florestais tropicais. Brasília: ABRATES, p. 83-135. 1993.

BRASIL. Ministério da Agricultura, Pecuária e Abastecimento. Regras para análise de sementes / Ministério da Agricultura, Pecuária e Abastecimento. Secretaria de Defesa Agropecuária. - Brasília: Mapa/ACS, 2009. 399 p. Disponível em: < http://www.agricultura.gov.br/assuntos/insumos-agropecuarios/arquivospublicacoes-insumos/2946_regras_analise_sementes.pdf >Acesso em: 22/01/2020.

CARDOSO, V.J.M. Temperature dependence on seed germination of a weed (Sidaglaziovii- Malvaceae). Naturalia, São Paulo, v.17, p.89-97, 1992.

CARVALHO, N.M.; NAKAGAWA, J. Germinação de sementes. In: CARVALHO, N.M.; NAKAGAWA, J. Sementes: ciência, tecnologia e produção. 4.ed. Jaboticabal: FUNEP, p.128-166. 2000.

FIGLIOLIA, M. B.; AGUIAR, I. B. de. SILVA, A. da. Germinação de sementes de três espécies arbóreas brasileiras. Rev. Inst. Flor., São Paulo, v. 21, n. 1, p. 107115, jun. 2009.

MARCOS FILHO, J.; CÍCERO, S. M.; SILVA, W. R. Avaliação da qualidade das sementes. Piracicaba: FEALQ, 1987. 230p.

MAYER, A.M.; POLJAKOFF-MAYBER, A. Factors affecting germination. In: MAYER, A.M.; POLJAKOFF-MAYBER, A. The germination of seeds. 3 ed. Oxford: Pergamon Press, 1982. p.22-49.

OLIVEIRA, R.P.; SCIVITTARO, W.B. Formação do porta-enxerto Trifoliata: época de semeadura e tegumento na emergência de plântulas. Ciência Rural, Santa Maria v.37, n. 1, p. 281-283, 2007.

OLIVEIRA, R.P.; SOARES FILHO, W.S.; PASSOS, O.S.; SCIVITTARO, W.B.; ROCHA, P.S.G. Produção de porta-enxertos de citros. In: OLIVEIRA, R.P.; SOARES FILHO, W.S.; PASSOS, O.S.; SCIVITTARO, W.B.; ROCHA, P.S.G. Portaenxertos para citros. Pelotas: Embrapa Clima Temperado, 2008. (Embrapa Clima Temperado. Documentos, 226).

SANTOS, P.C.M. Phytophthora nicotianae: ação de meios de cultura e da qualidade da luz no crescimento e esporulação e aspectos fisiológicos e bioquímicos da interação com porta-enxertos cítricos. 2015. Tese (Doutorado 
em Ciências) - Escola Superior de Agricultura Luiz de Queiroz - Universidade de São Paulo, Piracicaba, 2015.

SANTOS, S.R.G.; AGUIAR, I. B. Efeito da temperatura na germinação de sementes de Sebastiania commersoniana (Baillon) Smith \& Downs separadas pela coloração do tegumento. Scientia Forestalis, n. 69, p.77-83, dez., 2005.

SCHÄFER, G.; SOUZA, P.V.D.; DAUTD, R.H.S.; DORNELLES, A.L.C. Substratos na emergência de plântulas e expressão da poliembrioniaem porta-enxertos de citros. Ciência Rural, v.35, n.2, mar-abr, 2005.

SIQUEIRA, VASCONCELLOS, J.F.F.; DIAS, D.C.F.S.; PEREIRA, W.E. Germinação de sementes de porta-enxertos de citros após o armazenamento em ambiente refrigerado, Rev. Bras. Frutic., Jaboticabal - SP, v. 24, n. 2, p. 317-322, ago.; 2002.

TEIXEIRA, P.T.L.; SCHAFER, G.; SOUZA, P.V.D.; TODESCHINI, A. A escarificação química e o desenvolvimento inicial de porta-enxertos cítricos. Revista Brasileira de Fruticultura. v.31, n.3, Jaboticabal, set., 2009.

WILTBANK, W.J.; ROUSE, R.E.; KHOI, L.N. Influence of temperature on citrus rootstock seed emergence. Proceedings of the Florida State Horticultural Society, v.108, p.137-139, 1995. 